\title{
Association of risk factors with unfavorable outcomes after resection of adult benign intradural spine tumors and the effect of hospital volume on outcomes: an analysis of 18,297 patients across 774 US hospitals using the National Inpatient Sample (2002-2011)
}

\author{
*Piyush Kalakoti, MD, Symeon Missios, MD, Richard Menger, MD, Sunil Kukreja, MD, \\ Subhas Konar, MD, and Anil Nanda, MD, MPH
}

Department of Neurosurgery, Louisiana State University Health Sciences Center, Shreveport, Louisiana

\begin{abstract}
OBJECT Because of the limited data available regarding the associations between risk factors and the effect of hospital case volume on outcomes after resection of intradural spine tumors, the authors attempted to identify these associations by using a large population-based database.

METHODS Using the National Inpatient Sample database, the authors performed a retrospective cohort study that involved patients who underwent surgery for an intradural spinal tumor between 2002 and 2011. Using national estimates, they identified associations of patient demographics, medical comorbidities, and hospital characteristics with inpatient postoperative outcomes. In addition, the effect of hospital volume on unfavorable outcomes was investigated. Hospitals that performed fewer than 14 resections in adult patients with an intradural spine tumor between 2002 and 2011 were labeled as low-volume centers, whereas those that performed 14 or more operations in that period were classified as high-volume centers (HVCs). These cutoffs were based on the median number of resections performed by hospitals registered in the National Inpatient Sample during the study period.
\end{abstract}

RESULTS Overall, 18,297 patients across 774 hospitals in the United States underwent surgery for an intradural spine tumor. The mean age of the cohort was $56.53 \pm 16.28$ years, and $63 \%$ were female. The inpatient postoperative risks included mortality $(0.3 \%)$, discharge to rehabilitation $(28.8 \%)$, prolonged length of stay (> 75th percentile) $(20.0 \%)$, highend hospital charges (> 75th percentile) $(24.9 \%)$, wound complications $(1.2 \%)$, cardiac complications $(0.6 \%)$, deep vein thrombosis (1.4\%), pulmonary embolism (2.1\%), and neurological complications, including dural tears (2.4\%). Undergoing surgery at an $\mathrm{HVC}$ was significantly associated with a decreased chance of inpatient mortality $(\mathrm{OR} 0.39 ; 95 \% \mathrm{Cl}$ $0.16-0.98)$, unfavorable discharge (OR $0.86 ; 95 \% \mathrm{Cl} 0.76-0.98)$, prolonged length of stay (OR $0.69 ; 95 \% \mathrm{Cl} 0.62-0.77$ ), high-end hospital charges (OR $0.67 ; 95 \% \mathrm{Cl} 0.60-0.74)$, neurological complications (OR $0.34 ; 95 \% \mathrm{Cl} 0.26-0.44$ ), deep vein thrombosis (OR $0.65 ; 95 \% \mathrm{Cl} 0.45-0.94$ ), wound complications (OR $0.59 ; 95 \% \mathrm{Cl} 0.41-0.86$ ), and gastrointestinal complications (OR $0.65 ; 95 \% \mathrm{Cl} 0.46-0.92)$.

CONCLUSIONS The results of this study provide individualized estimates of the risks of postoperative complications based on patient demographics and comorbidities and hospital characteristics and shows a decreased risk for most unfavorable outcomes for those who underwent surgery at an HVC. These findings could be used as a tool for risk stratification, directing presurgical evaluation, assisting with surgical decision making, and strengthening referral systems for complex cases.

http://thejns.org/doi/abs/10.3171/2015.5.FOCUS15157

KEY WORDS intradural spine tumors; spine surgery; unfavorable outcomes; NIS; National Inpatient Sample

ABBREVIATIONS ARF = acute renal failure; $\mathrm{CAD}=$ coronary artery disease $; \mathrm{CCI}=$ Charlson Comorbidity Index; $\mathrm{CHF}=$ congestive heart failure; $\mathrm{CRF}=$ chronic renal failure; DM = diabetes mellitus; DVT = deep vein thrombosis; HCUP = Healthcare Cost and Utilization Project; HVC = high-volume center; ICD-9-CM = International Classification of Diseases, Ninth Revision, Clinical Modification; LOS = length of stay; LVC = low-volume center; NF = neurofibromatosis; NF-1, -2 = NF Type 1, Type 2; NIS = National Inpatient Sample; $\mathrm{PE}=$ pulmonary embolism; $\mathrm{PVD}=$ peripheral vascular disease; $\mathrm{SCT}=$ spinal cord tumor.

SUBMITTED April 1, 2015. ACCEPTED May 19, 2015. INCLUDE WHEN CITING DOI: 10.3171/2015.5.FOCUS15157.

DISCLOSURE The authors report no conflict of interest concerning the materials or methods used in this study or the findings specified in this paper.

* Drs. Kalakoti and Missios contributed equally to this work. 
$\mathrm{P}$ RIMARY spinal cord tumors (SCTs) are rare and account for $5 \%-15 \%$ of all adult spinal tumors ${ }^{28,56}$ and $2 \%-4 \%$ of primary CNS tumors. ${ }^{2}$ In the United States, an estimated 850-1700 new primary SCT cases are diagnosed each year. Contrary to their intracranial counterparts, primary SCTs are 10-15 times less frequent ${ }^{68}$ and do not exhibit an association between increasing malignancy grade and age at the time of presentation., ${ }^{2,16}$ Based on their anatomical location with respect to the dura, these tumors are broadly classified as being extradural or intradural. The extradural spine tumors are predominantly metastatic in origin and are considered by far the most common type of SCT, whereas the intradural tumors are subclassified as extramedullary or intramedullary. ${ }^{29}$ Among intradural spine tumors, intramedullary SCTs constitute 16\%-20\%, whereas the remainder are extramedullary tumors. ${ }^{20,51}$

Microsurgical resection is a well-acclaimed primary treatment modality for benign SCTs. Tumor type and grade have also been shown to influence outcomes. Although resection is considered safe and effective, , $^{21,26,34,46,55,59,60}$ postoperative complications vary based on patient comorbidities, tumor location, size, and extent, as well as hospital- and surgeon-related risk factors. Several singleinstitution studies ${ }^{14,27,49,52,68-72}$ have investigated long-term outcomes and associations of various preoperative risk factors with outcomes in patients undergoing resection for intradural spine tumors. Most of these retrospective analyses, however, are limited in the generalizability of their conclusions given their inherent selection bias. Prospective clinical studies ${ }^{47,50}$ are equally limited because of individual hospitals' limited sample size and geographic variations. In the era of heath care accountability, establishing quality metrics and identifying modifiable risk factors that contribute to adverse events are critical. Such knowledge can potentially aid during presurgical evaluation, shared decision making, and outcome prediction.

The National Inpatient Sample (NIS), the largest allpayer hospital inpatient database, represents a stratified validated sample of $20 \%$ of all inpatient admissions to nonfederal hospitals across the United States. Using this database, we identified independent associations of patient- and hospital-related characteristics with inpatient outcomes in patients who underwent resection for benign intradural spinal tumors. In addition, we explored the effect of hospital case volume on inpatient outcomes after resection of intradural spine tumors.

\section{Methods \\ Data Source}

The NIS, the largest publicly available all-payer database, developed for the Healthcare Cost and Utilization Project (HCUP) by the Agency of Healthcare Research and Quality in Rockville, MD, was the data source used for the current study. ${ }^{65}$ With approximately 1000 hospitals participating in the HCUP, the NIS contains inpatient data that represent a $20 \%$ stratified subsampling across all nonfederal hospitals in the United States. ${ }^{1}$ The inpatient data in the NIS are cataloged into clinically purposeful categories by using International Classification of Diseases, Ninth Revision, Clinical Modification (ICD-
9-CM) codes (HCUP Clinical Classifications Software for ICD-9-CM, available at http://www.hcup-us.ahrq.gov/ toolssoftware/ccs/ccs.jsp). More information on the NIS database can be accessed at http://www.hcup-us.ahrq.gov/ nisoverview.jsp.

\section{Cohort Definition}

The NIS database was queried for identification of adult patients ( $>18$ years of age) who underwent resection (ICD-9-CM procedure code 03.0, 03.4, 03.09, 81.0, or 81.00-81.08) for benign intradural spine tumors (ICD9-CM diagnosis code 225.3 or 225.4) in the United States between 2002 and 2011. To study benign intradural spine tumors exclusively, patients with primary malignant tumors of the cord (ICD-9-CM code 192.2) or spinal meninges (ICD-9-CM code 192.3), spinal metastasis (ICD-9CM codes 198.3-198.5), nerve sheath tumors (ICD-9-CM code 215), malignant CNS neoplasms of uncertain behavior (ICD-9-CM code 237.5), or nervous system tumors of contiguous or unspecified sites, including extradural tumors (ICD-9-CM code 192.8 or 192.9), were excluded from the study (Fig. 1).

\section{Patient and Hospital Characteristics}

The following patient demographics were used: age, sex, race, primary payer, and quartiles of average household income according to patient zip code. Patient characteristics with meager categorical values were condensed to obviate incongruous coefficients in the regression models. These characteristics included Native American race $(0.4 \%)$ and those with "no charge" as the payment source $(0.2 \%)$ and were designated as "other" race and "other" payment source, respectively. To quantify the effect of patient comorbidities, stratification of medical comorbidities was achieved by using the Charlson Comorbidity Index $(\mathrm{CCI})^{17,18}$ as adapted by Romano et al..$^{58}$ for use with ICD9-CM codes (Table 1).

The hospital characteristics coded in the NIS include hospital bed size, hospital teaching status, and region. In addition, the NIS contains an encrypted HCUP hospital identification number that is assigned to each case registered with it. Extrapolating the US national estimates, we used this variable to determine the frequency of resections for benign adult intradural spine tumors performed at each hospital registered in the NIS between the years 2002 and $2011(\mathrm{n}=774)$. Based on the number of these operations performed per hospital during these years, the median value was estimated ( $\mathrm{n}=14$ procedures). Based on the median cutoffs, each hospital was labeled as a lowvolume center (LVC) or a high-volume center (HVC). Subsequently, patients were deemed to have undergone surgery for intradural spine tumors at an LVC $(n=398)$ if the hospital performed fewer than 14 resections or at an HVC $(n=376)$ if the hospital performed $\geq 14$ resections between 2002 and 2011.

\section{Outcome Variables}

The primary outcome variables of interest were inpatient mortality, unfavorable discharge status (discharge to rehabilitation), prolonged length of stay (LOS), high- 


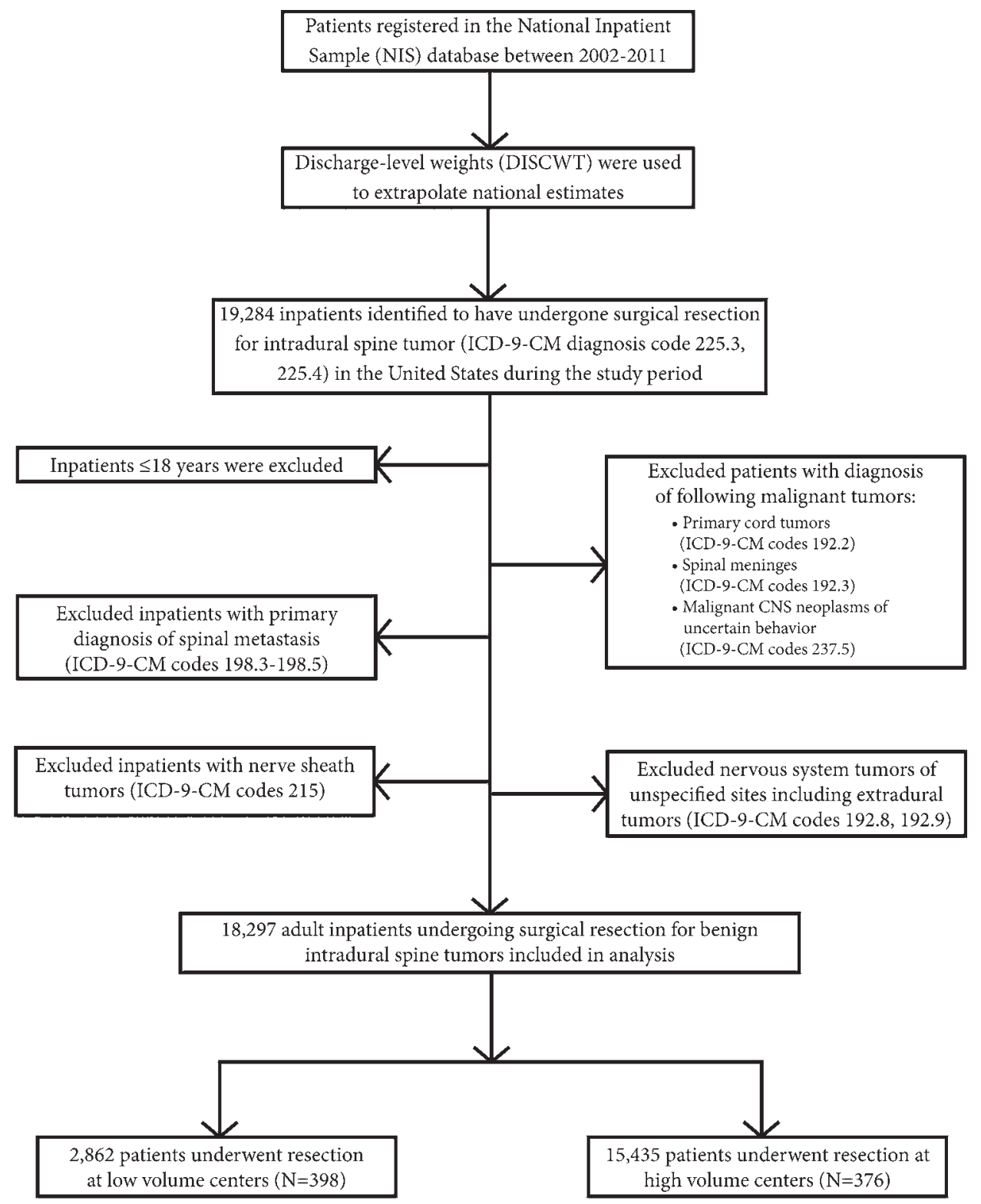

FIG. 1. Algorithm used for cohort selection in this study.

end hospital charges, and inpatient postoperative complications, which included deep vein thrombosis (DVT), pulmonary embolism (PE), wound infection, acute renal failure (ARF), and neurological, cardiac, wound, and gastrointestinal complications (Table 1). Transfer to a shortterm hospital, a skilled nursing facility, intermediate care, or rehabilitation was defined as an unfavorable discharge. Continuous outcome end points (LOS and hospital charges) were dichotomized. Patients with an LOS above the 75th percentile of the total number of days from admission to discharge were labeled as having had a prolonged LOS, whereas those billed for inpatient care that exceeded the 75th percentile of charges for the total cohort were labeled as having had a high-end hospital charge. The association of these outcomes with hospital case volume was determined.

\section{Statistical Analysis}

All statistical analysis was conducted using commercially available SPSS version 22.0 (IBM) and XLSTAT-Pro (Addinsoft, Paris, France) version 2014.5.03. Dischargelevel weights were used for all analyses to provide national estimates. Continuous variables are presented as means \pm $\mathrm{SD}$ or medians \pm interquartile range, as appropriate, and a comparison of the means was performed using the independent-samples t-test. Categorical values are depicted as numbers and percentages, and comparisons were evaluated using the Pearson chi-square test. For calculations related to hospital charges, inflation adjustments for each year over the 10-year study period were performed using the Bureau of Labor Statistics Consumer Price Index calculator (available at http://www.bls.gov/data/inflation_calculator.htm) to convert values into 2013 US dollar values. 
TABLE 1. Coding definitions (ICD-9-CM codes)

\begin{tabular}{|c|c|}
\hline Group/Category & ICD-9 Diagnosis or Procedure Code(s) \\
\hline Diagnosis, benign intradural spinal tumor & $225.3,225.4$ \\
\hline Procedure, tumor resection & $03.0,03.01,03.02,03.09,03.32,03.4,81.0,81.00-81.08$ \\
\hline \multicolumn{2}{|l|}{ Independent (exposure) variables } \\
\hline Sex & - \\
\hline Age & - \\
\hline Sensory deficit & 782.0 \\
\hline Myelopathy & $336.3,336.8,336.9$ \\
\hline Syringomyelia & 336.0 \\
\hline Plegia & $\begin{array}{l}344.0,344.00-344.04,344.09,344.1,344.2,344.3,344.30-344.32,344.4,344.40-344.42, \\
344.5,344.6,344.60,344.61,344.8,344.81,344.89,344.9\end{array}$ \\
\hline Bowel/bladder dysfunction & $787.6,787.60,788.2,788.20,788.29,788.31-788.33,788.39,788.41,788.61,788.63-788.65$ \\
\hline NF-1 & 237.71 \\
\hline NF-2 & $237.7,237.70,237.72$ \\
\hline CAD & $\begin{array}{l}\text { 410, } 410.0-410.9,411,411.1,411.89,412,413,413.1,413.9,414,414.2,414.3,414.4,414.8 \\
414.9\end{array}$ \\
\hline Chronic pulmonary disease & $490-492.8,493.00-493.91,494,495.0-505,506.4$ \\
\hline CRF & 585,586, V42.0, V45.1, V56.0, V56.8 \\
\hline Hypertension & $401,402,403,404$ \\
\hline Hypercholesterolemia & $272,272.0,272.1,272.2,272.3,272.4$ \\
\hline Smoking & $305.1, \mathrm{~V} 15.82,989.84$ \\
\hline Obesity & $278.00,278.01$ \\
\hline Alcohol abuse & $291.1,291.2,291.5,291.8,291.9,303.90-303.93,305.00-305.03$, V113 \\
\hline Coagulopathy & $286.0-286.9,287.1,287.3-287.5$ \\
\hline $\mathrm{CHF}$ & $398.91,402.01,402.11,402.91,404.01,404.03,404.11,404.13,404.91,404.93,428.0-428.9$ \\
\hline DM & $250.00-250.33,250.40-250.73,250.90-250.93$ \\
\hline PVD & $440.00-440.9,441.2,441.4,441.7,441.9,443.1-443.9,447.1,557.1,557.9,785.4$, V43.4 \\
\hline \multicolumn{2}{|l|}{ Outcome \& complications } \\
\hline Unfavorable discharge & - \\
\hline Prolonged LOS (>75th percentile) & - \\
\hline High-end hospital charges (>75th percentile) & - \\
\hline Neurological complications including CSF leak & $349.1,349.3,349.31,349.39,953.0-953.9,996.2,996.75,997.0,997.00-997.02,997.09$ \\
\hline DVT & $\begin{array}{l}451.1,451.11,451.19,451.2,451.81,451.9,453.2-453.4,453.6,453.8,453.81-453.89,453.9 \\
38.7\end{array}$ \\
\hline PE & $415.1,415.11,415.13,415.19, \mathrm{~V} 12.51$ \\
\hline Wound complications & $998.10-998.19,998.30-998.39$ \\
\hline Cardiac complications & 997.1 \\
\hline Respiratory complications & $518.51-518.53,518.81,518.82,518.84,997.3,997.31,997.32,997.39,998.81$ \\
\hline Wound infection & $996.6,996.63,998.02,998.5,998.51,998.59$ \\
\hline ARF & $584,584.5,584.6,584.7,584.8,584.9$ \\
\hline Gastrointestinal complications & $997.4,997.41,997.49$ \\
\hline
\end{tabular}

A multivariable binary logistic regression analysis using the "Enter" method was performed to identify independent associations of patient and hospital characteristics with the above-defined outcome variables. The regression analysis was controlled for age, sex, race (African American, Hispanic, Asian, or other, with Caucasian as the reference), income quartile (second, third, or fourth with reference to the first income quartile), primary payer (Medicaid, private including health maintenance organization, selfpayer, or other, with Medicare as the reference), patient comorbidities (Table 1), hospital region (West, South, or Midwest, with Northeast as the reference), teaching status (urban nonteaching or urban teaching, with rural as the reference), bed size (small, medium, or large), and hospital case volume, as defined above (LVC being the reference). Age was entered as a continuous variable. The patientlevel comorbidities included were neurofibromatosis Type 1 (NF-1), NF-2, presence of preoperative sensory deficit, syringomyelia, myelopathy, extremity plegia, bowel and bladder dysfunction, and medical comorbidities, including 
Inpatient Mortality

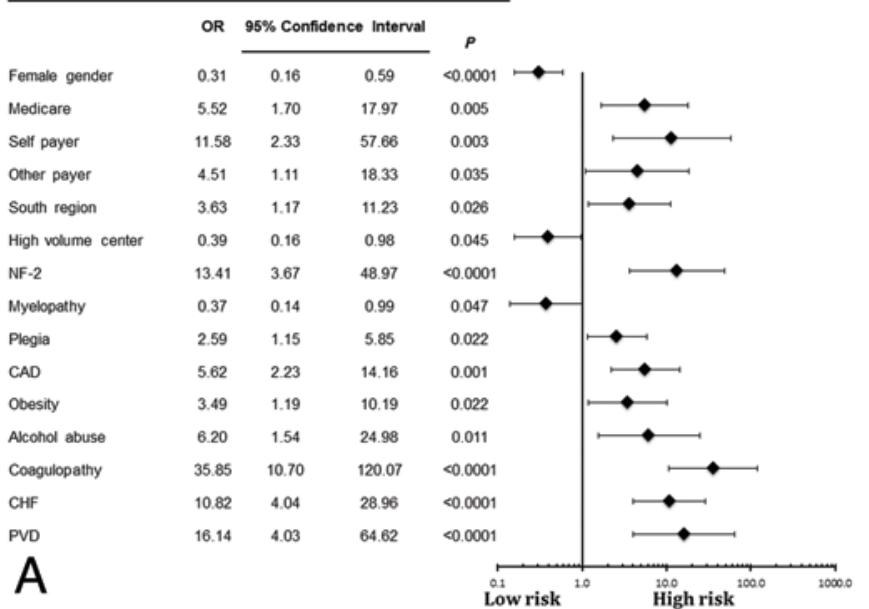

\section{Prolonged LOS $\left(>75^{\text {th }}\right.$ percentile)}
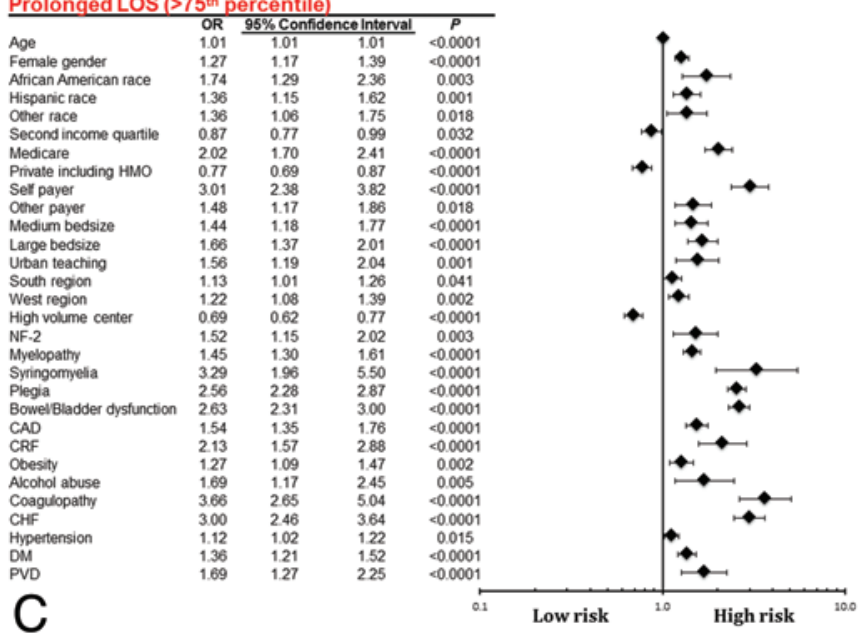
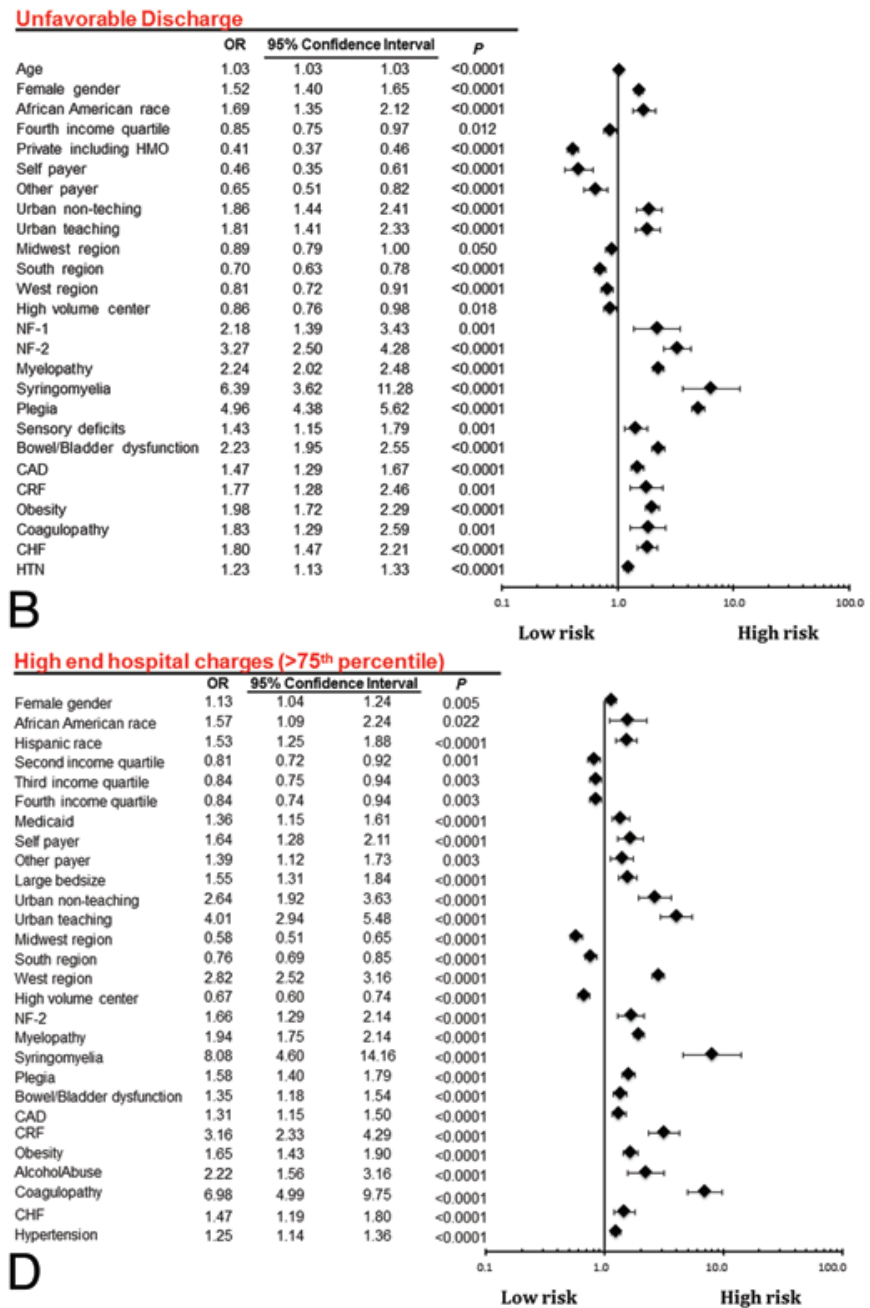

FIG. 2. Multivariable binary logistic regression model demonstrating the association of independent patient and hospital-related risk factors with inpatient mortality (A), unfavorable discharge (B), prolonged LOS (> 75th percentile) (C), and high-end hospital charges (> 75th percentile) (D). The corresponding forest plots are displayed on the right in each panel. HMO = health maintenance organization; $\mathrm{HTN}=$ hypertension.

coronary artery disease (CAD), chronic pulmonary disease, chronic renal failure (CRF), obesity, alcohol abuse, coagulopathy, congestive heart failure (CHF), hypertension, diabetes mellitus (DM), and peripheral vascular disease (PVD) (Table 1). In addition, the association of outcomes at HVCs with reference to those at LVCs was examined. Odds ratios and 95\% confidence intervals are reported for all associations that attained statistical significance and are depicted in corresponding forests plots in Figs. 2-4.

Multiple imputation was performed for variables with missing values included in the regression model. These variables included age $(0.2 \%)$, sex $(0.7 \%)$, race $(23.2 \%)$, primary payer $(0.1 \%)$, income quartile $(2.0 \%)$, hospital bed size $(0.3 \%)$, and teaching status $(0.3 \%)$. Patterns of missing variables suggested that the missing values were completely random; multiple imputation was performed in SPSS on the basis of the existing covariables. The original data were iterated 5 times to create 5 imputed data sets. These imputed data sets were merged to generate a pooled data set with no subsequent missing values. Imputed data sets were used for all of the regression analyses.

Regression diagnostics was conducted for each logistic regression model. The $\mathrm{C}$-index statistic or the area under the receiver operating characteristic (ROC) curve was calculated. Each statistical test was 2 -sided, and a $\mathrm{p}$ value of $<0.05$ was interpreted as statistically significant.

\section{Results}

\section{Patient Characteristics}

Between 2002 and 2011, 18,297 adult patients underwent resection for intradural spine tumors across 774 hospitals in the United States. The mean age of the cohort was $56.53 \pm 16.28$ years, and $63 \%$ were female. Patient demographics and clinical characteristics across LVCs and HVCs are presented in Table 2.

\section{Clinical Outcomes}

The overall observed outcomes included $0.3 \%$ inpa- 

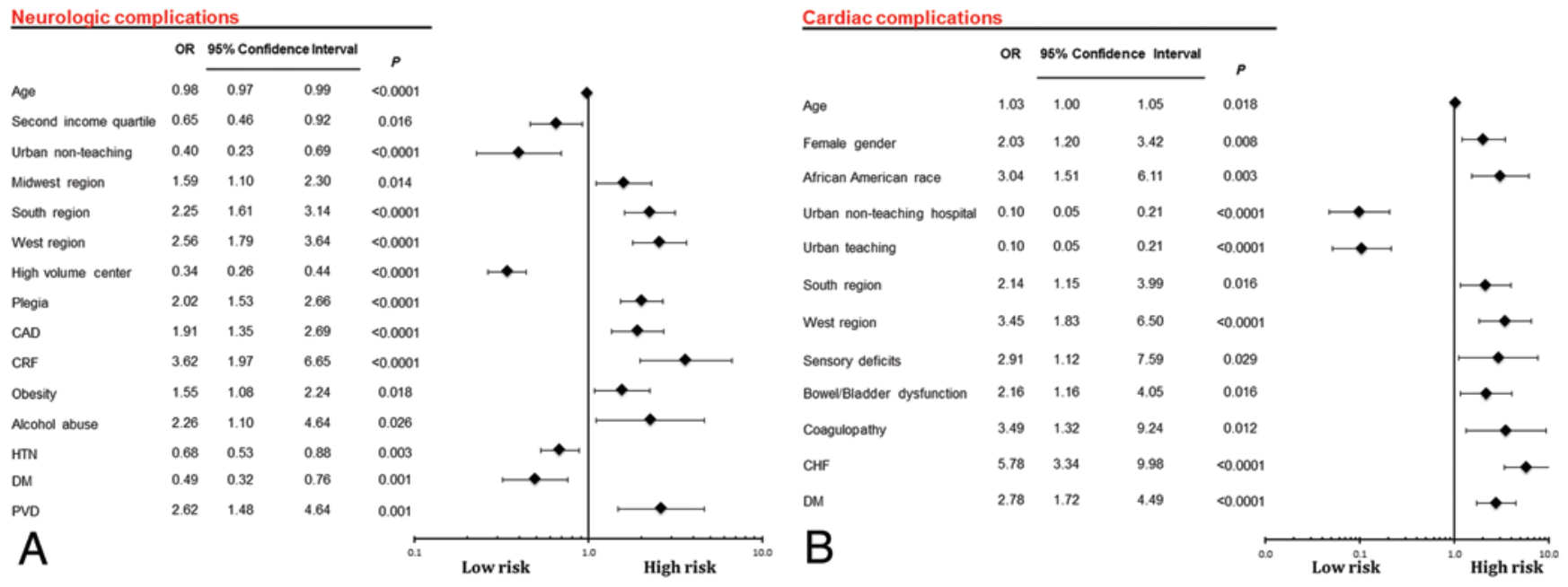

Deep Venous Thrombosis
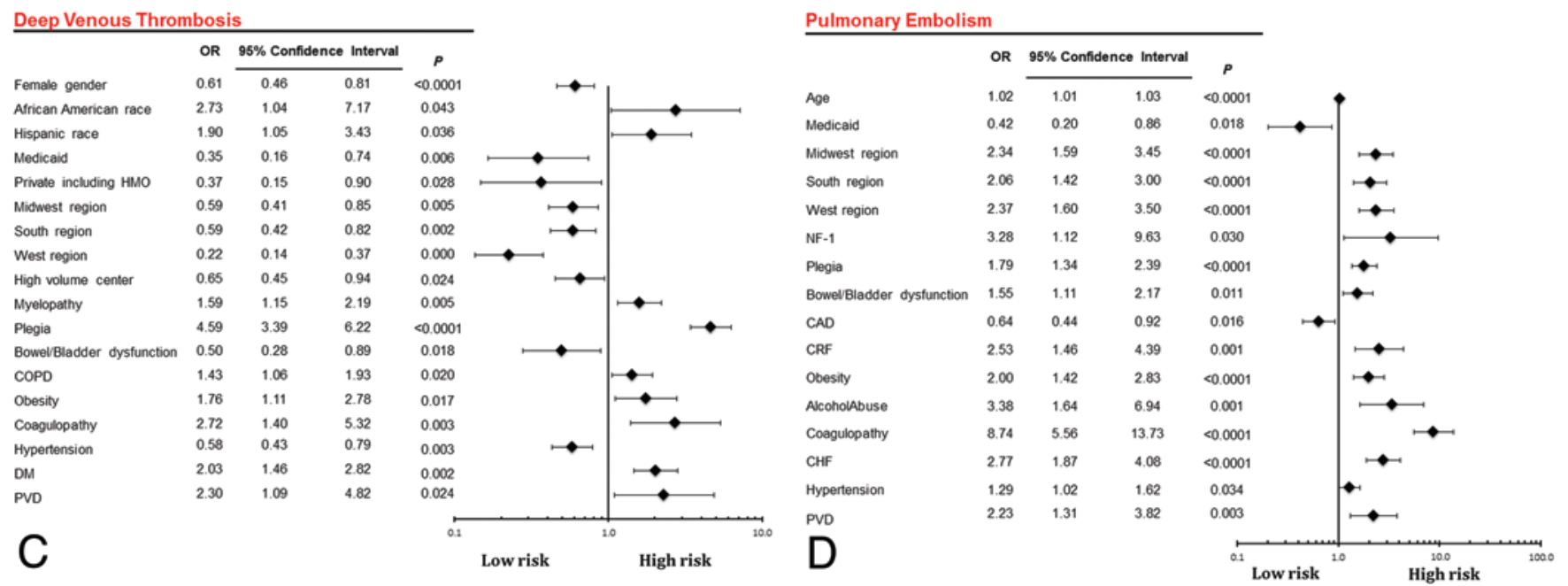

FIG. 3. Multivariable binary logistic regression model demonstrating the association of independent patient and hospital-related risk factors with postoperative neurological complications including dural tear (A), cardiac complications (B), DVT (C), and PE (D). The corresponding forest plots are displayed on the right in each panel. COPD = chronic obstructive pulmonary disease.

tient death, 28.8\% unfavorable discharge, $20 \%$ prolonged LOS ( $>75$ th percentile), $24.9 \%$ high-end hospital charges (> 75th percentile), $2.4 \%$ neurological complications, $1.4 \%$ DVT, $2.1 \%$ PE, $1.2 \%$ wound complications, $0.6 \%$ infection, $0.6 \%$ cardiac complications, $1.4 \%$ respiratory complications, $1.4 \%$ gastrointestinal complications, and $0.7 \%$ ARF. Patients who underwent tumor resection at an LVC had higher rates of unfavorable outcomes than those whose surgery was performed at an HVC. The distribution of these outcomes across LVCs and HVCs is noted in Table 3.

\section{Regression Model Derivation}

The associations of independent risk factors with the likelihood of inpatient mortality (Fig. 2A), unfavorable discharge (Fig. 2B), prolonged LOS (> 75th percentile) (Fig. 2C), high-end hospital charges ( $>75$ th percentile) (Fig. 2D), neurological complications (Fig. 3A), cardiac complications (Fig. 3B), DVT (Fig. 3C), PE (Fig. 3D), wound complications (Fig. 4A), and infection (Fig. 4B) were determined in a multivariable binary regression anal- ysis. In addition, the association of these outcomes with hospital case volume status was investigated. Operations at an HVC were significantly associated with a decreased chance of inpatient mortality (OR 0.39; 95\% CI 0.16-0.98), unfavorable discharge (OR 0.86; 95\% CI 0.76-0.98), prolonged LOS (OR 0.69; 95\% CI 0.62-0.77), high-end hospital charges (OR 0.67; 95\% CI 0.60-0.74), neurological complications (OR 0.34; 95\% CI 0.26-0.44), DVT (OR $0.65 ; 95 \%$ CI $0.45-0.94$ ), wound complications (OR 0.59; 95\% CI 0.41-0.86), and gastrointestinal complications (OR 0.65; 95\% CI 0.46-0.92) (Fig. 5). The regression analysis was controlled for age, sex, race, income quartile, primary payer, hospital bed size, hospital teaching status, geographical region, hospital case volume, and patient-level comorbidities (Table 1).

\section{Accuracy of the Model}

The area under the curve was used to quantify the discriminatory ability of the regressions. The areas under the curve were 0.95 for inpatient mortality $(95 \%$ CI $0.93-0.98$; $\mathrm{p}<0.0001), 0.80$ for unfavorable discharge $(95 \%$ CI $0.79-$ 


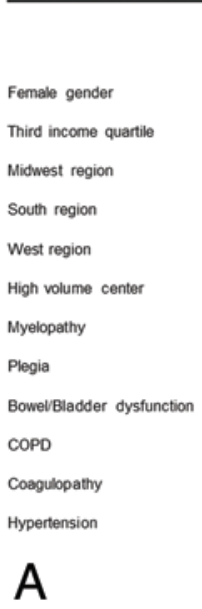

\begin{tabular}{ll} 
OR & $95 \%$ Confidence \\
\cline { 2 - 2 } 0.72 & 0.54 \\
0.52 & 0.27 \\
2.26 & 1.33 \\
1.76 & 1.04 \\
3.39 & 2.01 \\
0.59 & 0.41 \\
2.15 & 1.56 \\
4.28 & 3.16 \\
2.82 & 1.97 \\
1.82 & 1.23 \\
8.99 & 4.89 \\
2.30 & 1.66 \\
&
\end{tabular}

FIG. 4. Multivariable binary logistic regression model demonstrating the association of independent patient and hospital-related risk factors with postoperative wound complications $(A)$ and infection $(B)$. The corresponding forest plots are displayed on the right in each panel.

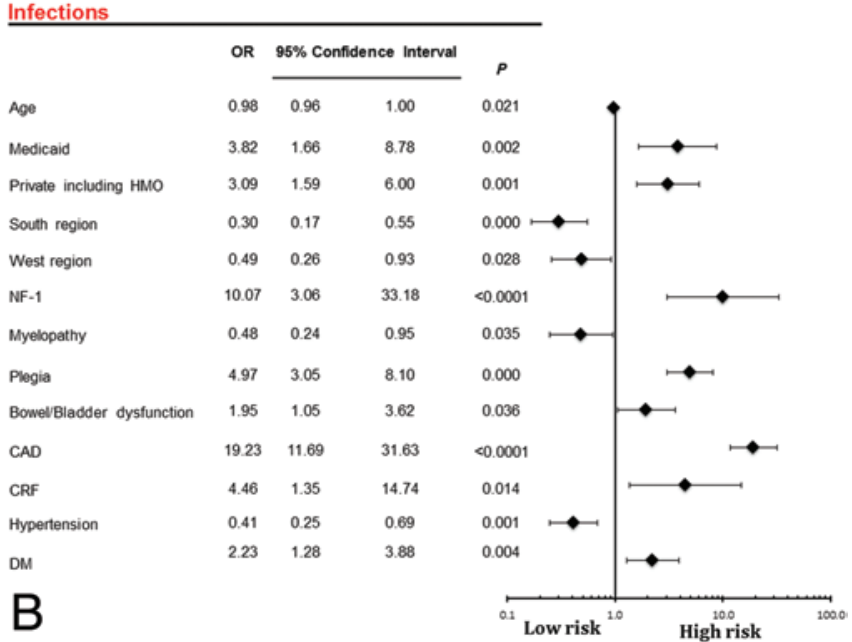

$0.81 ; \mathrm{p}<0.0001), 0.74$ for prolonged LOS $(>75$ th percentile) (95\% CI $0.73-0.75 ; \mathrm{p}<0.0001)$, 0.74 for high-end charges ( $>75$ th percentile) $(95 \%$ CI $0.73-0.75 ; \mathrm{p}<0.0001)$, 0.76 for neurological complications (95\% CI 0.73-0.79; p $<0.0001), 0.87$ for cardiac complications (95\% CI 0.85$0.90 ; \mathrm{p}<0.0001), 0.84$ for DVT $(95 \%$ CI $0.81-0.86$; $\mathrm{p}<$ $0.0001), 0.82$ for PE (95\% CI $0.80-0.85$; $\mathrm{p}<0.0001), 0.88$ for wound complications (95\% CI 0.86-0.90; $\mathrm{p}<0.0001$ ), and 0.90 for infection (95\% CI 0.87-0.94; $\mathrm{p}<0.0001$ ).

\section{Discussion}

In the current era of health care accountability and in a consumer-driven health system, identification and quantification of risk factors associated with detrimental outcomes are essential for benchmarking outcomes and ensuring quality in surgical health care delivery. ${ }^{33}$ To define these quality metrics and risk estimators, a large population database that incorporates hospitals from various geographical locations, a broad range of academic and private centers, and diverse clinical practice settings is essential for obtaining generalizable conclusions. The NIS is a prospective discharge database representative of a large US population from which extrapolation for national estimates can be performed, enabling reliable risk-factor identification.

In this nationwide study, 18,297 adult patients from across the United States were examined to identify independent patient- and hospital-related factors associated with unfavorable postoperative outcomes after resection for intradural spinal tumors. From a multivariable regression analysis performed using extrapolated population values while controlling for preoperative comorbidities and hospital characteristics, our results quantify the likelihood of unfavorable outcomes after resection in these patients. Patients with preoperative extremity plegia, NF-2, CAD, obesity, coagulopathy, or CHF tended to have a higher likelihood of inpatient mortality, unfavorable discharge, prolonged LOS, and high-end hospital charges. Myelopa- thy, plegia, and bowel/bladder dysfunction also predisposed patients toward an increased likelihood of developing postoperative cardiac complications, DVT, wound infection, and other wound complications. In an extensive systematic analysis on intradural spinal tumors, Harrop et al. ${ }^{39}$ concluded that a patient's preoperative neurological status is a determining factor for long-term neurological and functional outcome after surgery. Nambiar and Ka$\operatorname{var}^{52}$ also identified lower preoperative McCormick and tumor grades and extramedullary location as independent predictors for good neurological outcome.

Racial disparities in health care services, resource utilization, complications, and outcomes have been analyzed extensively by health care researchers over the past few decades and are notable in various neurosurgical procedures, including spine surgeries. . $^{3,10,15,25,35,37,44,53,62,66}$ In our analysis, African American race was noted to confer a higher likelihood than Caucasian race of unfavorable discharge (OR 1.69; 95\% CI 1.35-2.12; p <0.0001), prolonged LOS (OR 1.74; 95\% CI 1.29-2.36; $\mathrm{p}=0.003$ ), high-end hospital charges (OR 1.57; 95\% CI 1.09-2.24; $\mathrm{p}=0.022$ ), cardiac complications (OR 3.04; 95\% CI 1.51-6.11; p = 0.003 ), and DVT (OR 2.73; 95\% CI 1.04-7.17; $\mathrm{p}=0.043$ ) after benign tumor resection. Inequalities in access to routine health care services, secondary to lower socioeconomic conditions, for maintaining modifiable preexisting comorbidities seem a reasonable explanation for the racial disparity seen in outcomes for African Americans. Conversely, patients in higher income quartiles had significantly lower odds for an unfavorable discharge (OR 0.85; 95\% CI 0.75-0.97; $\mathrm{p}=0.012$ ), prolonged LOS (OR 0.87; 95\% CI 0.77-0.99; $\mathrm{p}=0.032)$, high-end hospital charges (OR 0.84; 95\% CI 0.74-0.94; p = 0.003), and postoperative neurological (OR 0.65; 95\% CI 0.46-0.92; $\mathrm{p}=0.016$ ) and wound (OR 0.52; 95\% CI 0.27-0.99; $\mathrm{p}=0.047$ ) complications. Patients with private insurance are assumed to have better primary care access, which contributes to better maintenance of medical conditions. To this effect, our data show that patients with private insurance had a lower 
TABLE 2. Demographics and clinical characteristics of 18,297 patients who underwent resection for intradural spinal tumors across 774 nonfederal hospitals in the United States between 2002 and 2011

\begin{tabular}{|c|c|c|c|c|}
\hline Demographics \& Characteristics & Overall $(n=18,297)$ & $\operatorname{LVCs}(n=2,862)$ & HVCs $(n=15,435)$ & $p$ Value \\
\hline \multicolumn{5}{|l|}{ Demographics } \\
\hline Age (mean \pm SD) (yrs) & $56.53 \pm 16.28$ & $58.04 \pm 16.90$ & $56.24 \pm 16.14$ & $<0.0001^{*}$ \\
\hline Female sex (no. [\%])† & $11,476(63.2)$ & $1838(64.7)$ & $9638(62.9)$ & 0.208 \\
\hline \multicolumn{5}{|l|}{ Race (no. $[\%]) \dagger$} \\
\hline Caucasian & 10,797 (76.8) & $1655(74.3)$ & $9142(77.3)$ & 0.554 \\
\hline African American & $1090(7.8)$ & $204(9.2)$ & $886(7.5)$ & $0.026^{*}$ \\
\hline Hispanic & $1027(7.3)$ & $184(8.3)$ & $843(7.1)$ & 0.148 \\
\hline Asian & $626(4.5)$ & $86(3.9)$ & $540(4.6)$ & 0.359 \\
\hline Other & $514(3.6)$ & $96(4.3)$ & $418(3.5)$ & 0.170 \\
\hline \multicolumn{5}{|l|}{ Income (no. [\%])† } \\
\hline Lowest quartile & $3191(17.8)$ & $504(18.1)$ & $2687(17.7)$ & 0.930 \\
\hline Second quartile & $4119(23.0)$ & $704(25.2)$ & $3415(22.6)$ & $0.009^{*}$ \\
\hline Third quartile & $4508(25.1)$ & $708(25.3)$ & $3800(25.2)$ & 0.961 \\
\hline Fourth quartile & $6117(34.1)$ & $877(31.4)$ & $5240(34.6)$ & $0.005^{*}$ \\
\hline \multicolumn{5}{|l|}{ Primary payer (no. [\%])† } \\
\hline Medicare & $6358(34.8)$ & $1120(39.2)$ & $5238(34.0)$ & $<0.0001^{*}$ \\
\hline Medicaid & $1138(6.2)$ & $180(6.3)$ & $958(6.2)$ & 0.986 \\
\hline Private & $9772(53.5)$ & $1389(48.6)$ & $8383(54.4)$ & $<0.0001^{*}$ \\
\hline Self & $430(2.4)$ & $85(3.0)$ & $345(2.2)$ & 0.058 \\
\hline Other & 569 (3.1) & $83(2.9)$ & $486(3.2)$ & 0.781 \\
\hline \multicolumn{5}{|l|}{ Teaching status (no. [\%])† } \\
\hline Rural & $538(2.9)$ & $134(4.7)$ & $404(2.6)$ & $<0.0001^{*}$ \\
\hline Urban nonteaching & $4628(25.4)$ & $1648(57.8)$ & $2980(19.3)$ & $<0.0001^{*}$ \\
\hline Urban teaching & $13,090(71.7)$ & $1070(37.5)$ & $12,020(78.1)$ & $<0.0001^{*}$ \\
\hline \multicolumn{5}{|l|}{ Bed size (no. [\%])† } \\
\hline Small & $1114(6.1)$ & $364(12.8)$ & $750(4.9)$ & $<0.0001^{*}$ \\
\hline Medium & $3389(18.6)$ & $727(25.5)$ & 2662 (17.3) & $<0.0001^{*}$ \\
\hline Large & $13,753(75.3)$ & $1761(61.7)$ & $11,992(77.8)$ & $<0.0001^{*}$ \\
\hline \multicolumn{5}{|l|}{ Region (no. [\%]) } \\
\hline Northeast & $3716(20.3)$ & $586(20.5)$ & $3130(20.3)$ & 0.972 \\
\hline Midwest & $3866(21.2)$ & $700(24.5)$ & $3166(20.5)$ & $<0.0001^{*}$ \\
\hline South & $6536(35.7)$ & $1003(35.0)$ & $5533(35.8)$ & 0.713 \\
\hline West & $4179(22.8)$ & $573(20.0)$ & $3606(23.4)$ & $<0.0001^{*}$ \\
\hline \multicolumn{5}{|l|}{ Hospital charges (US\$)‡ } \\
\hline Mean & 59,261 & 62,248 & 58,690 & $0.035^{*}$ \\
\hline Median (IQR) & $43,171(40,955)$ & $44,560(47,394)$ & $42,961(39,663)$ & \\
\hline \multicolumn{5}{|l|}{ Clinical characteristics (no. [\%]) } \\
\hline NF-1 & $105(0.6)$ & $11(0.3)$ & $94(0.6)$ & 0.090 \\
\hline NF-2 & $426(2.3)$ & $51(1.8)$ & $375(2.4)$ & $0.035^{*}$ \\
\hline Sensory deficits & $498(2.7)$ & $100(3.5)$ & $398(2.6)$ & $0.006^{*}$ \\
\hline Syringomyelia & $65(0.3)$ & $11(0.3)$ & $54(0.3)$ & 0.997 \\
\hline Myelopathy & $2523(13.8)$ & $323(11.3)$ & $2200(14.3)$ & $<0.0001^{*}$ \\
\hline Plegia & $1649(9.0)$ & $336(11.7)$ & $1313(8.5)$ & $<0.0001^{*}$ \\
\hline Bowel/bladder dysfunction & $1345(7.4)$ & $203(7.1)$ & $1142(7.4)$ & 0.564 \\
\hline CAD & $1494(8.2)$ & $263(9.2)$ & $1231(8.0)$ & $0.029^{*}$ \\
\hline COPD & $3399(18.6)$ & $525(18.3)$ & $2874(18.6)$ & 0.727 \\
\hline CRF & $210(1.1)$ & $40(1.4)$ & $170(1.1)$ & 0.172 \\
\hline Hypercholesterolemia & $3077(16.8)$ & $512(17.9)$ & $2565(16.6)$ & 0.094 \\
\hline Smoking & $2879(15.7)$ & $385(13.5)$ & 2494 (16.2) & $<0.0001^{*}$ \\
\hline Obesity & $1245(6.8)$ & $214(7.5)$ & $1031(6.7)$ & 0.119 \\
\hline Alcohol abuse & $171(0.9)$ & $20(0.7)$ & $151(1.0)$ & 0.153 \\
\hline
\end{tabular}


TABLE 2. Demographics and clinical characteristics of 18,297 patients who underwent resection for intradural spinal tumors across 774 nonfederal hospitals in the United States between 2002 and 2011 (continued)

\begin{tabular}{|c|c|c|c|c|}
\hline Demographics \& Characteristics & Overall $(n=18,297)$ & $\operatorname{LVCs}(n=2,862)$ & HVCs $(n=15,435)$ & $p$ Value \\
\hline \multicolumn{5}{|l|}{ Clinical characteristics (no. [\%]) (continued) } \\
\hline Coagulopathy & $191(1.0)$ & $28(1.0)$ & $163(1.1)$ & 0.708 \\
\hline $\mathrm{CHF}$ & $539(2.9)$ & $89(3.1)$ & $450(2.9)$ & 0.571 \\
\hline Hypertension & $7501(41.0)$ & $1280(44.7)$ & $6221(40.3)$ & $<0.0001^{*}$ \\
\hline $\mathrm{DM}$ & $2228(12.2)$ & $391(13.7)$ & $1837(11.9)$ & $0.008^{*}$ \\
\hline PVD & $272(1.5)$ & $63(2.2)$ & $209(1.4)$ & $0.001^{*}$ \\
\hline \multicolumn{5}{|l|}{$\mathrm{CCl}$} \\
\hline Low (0-2) & $17,897(97.9)$ & $2790(97.5)$ & $15,107(97.9)$ & 0.279 \\
\hline Moderate/high ( $\geq 3$ ) & $400(2.1)$ & $72(2.5)$ & $328(2.1)$ & \\
\hline LOS (mean [median]) (days) & $5.77(4)$ & $6.06(5)$ & $5.71(4)$ & $<0.0001^{*}$ \\
\hline
\end{tabular}

$\mathrm{COPD}=$ chronic obstructive pulmonary disease; $I \mathrm{QR}=$ interquartile range.

* Significant result.

$\dagger$ Values and percentages reported were computed based on excluding the missing values for gender $(0.7 \%)$, race $(23.2 \%)$, income quartile $(2.0 \%)$, primary payer $(0.1 \%)$, teaching status $(0.3 \%)$, and bed size $(0.3 \%)$.

$\ddagger$ Inflation-adjusted values over the 10-year period to 2013 US\$ amounts using the Bureau of Labor Statistics Consumer Price Index calculator (http://www.bls.gov/ data/inflation_calculator.htm).

likelihood of unfavorable discharge (OR $0.41 ; 95 \%$ CI 0.37-0.46; $\mathrm{p}<0.0001$ ), prolonged LOS (OR 0.77; 95\% CI 0.69-0.87; $<<0.0001$ ), and postoperative DVT (OR 0.37; 95\% CI 0.15-0.90; $\mathrm{p}=0.028$ ). Advancing age was associated with higher risks for unfavorable discharge (OR 1.03; 95\% CI 1.03-1.03; $\mathrm{p}<0.0001$ ), prolonged LOS (OR 1.01; 95\% CI 1.01-1.01; $\mathrm{p}<0.0001)$, cardiac complications (OR 1.03 ; 95\% CI 1.00-1.05; $\mathrm{p}=0.018$ ), and PE (OR 1.02; 95\% CI 1.01-1.03; $\mathrm{p}<0.0001)$ after benign tumor resection. In a nationwide analysis on SCTs, Patil et al..$^{57}$ found that age greater than 64 years had an increasingly significant association with postoperative adverse outcome. Sharma et al. ${ }^{61}$ also observed a higher likelihood of an adverse event in middle-aged and elderly patients after SCT surgery. This quantification of the observed association of advancing age and adverse outcomes in our study, although critical for decision making, should not deter elderly patients with an optimal risk profile from undergoing benign intradural tumor surgery.

In addition to the patient's preoperative symptoms and comorbidities, hospital volume has been significantly associated with patient-related outcomes. ${ }^{13,19,36,41,45}$ This relationship is most profound in patients undergoing procedures that are not commonly performed..$^{38}$ Studies investi-

TABLE 3. Postoperative outcomes in patients who underwent spinal intradural tumor resection across 774 nonfederal hospitals in the United States between 2002 and 2011

\begin{tabular}{|c|c|c|c|c|}
\hline \multirow[b]{2}{*}{ Complication } & \multicolumn{3}{|c|}{ No. of Patients (\%) } & \multirow[b]{2}{*}{$\mathrm{p}$ Value } \\
\hline & Overall $(n=18,297)$ & $\operatorname{LVCs}(n=2862)$ & HVCs $(n=15,435)$ & \\
\hline Inpatient mortality & $60(0.3)$ & $11(0.4)$ & $49(0.3)$ & 0.568 \\
\hline Unfavorable discharge* & $5235(28.8)$ & $920(32.4)$ & $4315(28.2)$ & $<0.0001 \dagger$ \\
\hline High-end hospital charges* & $4360(24.9)$ & $772(27.5)$ & $3558(24.4)$ & $0.001 \dagger$ \\
\hline Prolonged LOS (days) ${ }^{*}$ & $3639(20.0)$ & $653(23.0)$ & 2986 (19.5) & $<0.0001 \dagger$ \\
\hline Cardiac complications $\ddagger$ & $113(0.6)$ & $18(0.6)$ & $95(0.6)$ & 0.935 \\
\hline Neurologic complications including CSF leakł & $430(2.4)$ & $125(4.4)$ & $305(2.0)$ & $<0.0001 \dagger$ \\
\hline PE $\ddagger$ & $384(2.1)$ & $60(2.1)$ & $324(2.1)$ & 0.990 \\
\hline DVT‡ & $248(1.4)$ & $48(1.7)$ & $200(1.3)$ & 0.106 \\
\hline Wound complications $\ddagger$ & $223(1.2)$ & $52(1.8)$ & $171(1.1)$ & $0.002 \dagger$ \\
\hline ARF $\ddagger$ & $125(0.7)$ & $11(0.4)$ & $114(0.7)$ & $0.034 \dagger$ \\
\hline Wound infection $\ddagger$ & $110(0.6)$ & $20(0.7)$ & $90(0.6)$ & 0.463 \\
\hline Respiratory complicationsł & $255(1.4)$ & $47(1.7)$ & $208(1.4)$ & 0.219 \\
\hline Gastrointestinal complications & $262(1.4)$ & $54(1.9)$ & $208(1.4)$ & $0.026 \dagger$ \\
\hline
\end{tabular}

* Reported values exclude patients with inpatient mortality and missing values in the NIS.

$\dagger$ Significant result.

$\ddagger$ Reported values exclude patients with inpatient mortality. 


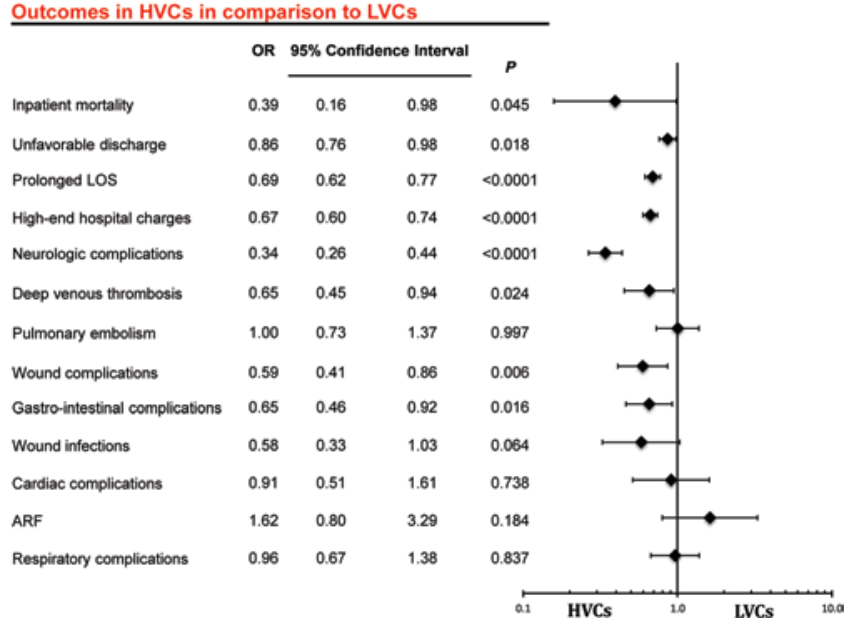

FIG. 5. Multivariable binary logistic regression analysis of unfavorable outcomes in HVCs in comparison with those in LVCs.

gating quality metrics across various hospital centers have consistently reported lower complication rates and superior postoperative outcomes for various neurosurgical procedures (including microvascular decompression, ${ }^{43}$ epilepsy surgery, ${ }^{30}$ endovascular and surgical management of aneurysms, ${ }^{6,11,40}$ craniotomy for subarachnoid hemorrhage, ${ }^{4,22}$ ventriculoperitoneal shunt operations,${ }^{64}$ and intracranial tumor surgery for primary brain tumors, ${ }^{8,63}$ metastatic brain tumors, ${ }^{5}$ meningioma, ${ }^{23}$ excision of acoustic neuroma, ${ }^{7}$ and pituitary tumors, ${ }^{9}$ and deep brain stimulation ${ }^{42}$ ) performed at HVCs. An inverse relationship between adverse outcomes and high provider volume has also been described for some spinal procedures, including surgeries on the lumbar spine ${ }^{32}$ and for lumbar stenosis. ${ }^{24}$

Although the underlying mechanisms that account for these volume-outcome associations are unclear, it is plausible that increased procedural performance is instrumental in better outcomes. To the best of our knowledge, the hospital volume-outcome relationship has not been investigated for patients with intradural spine tumors. Furthermore, it is critical for both patients and surgeons to know the cutoff values for hospital volumes associated with superior postoperative outcomes.

Intradural spinal cord surgery poses higher risks and technical challenges than does standard extradural spinal surgery for tumors or degenerative indications. Our findings indicate that operations for intradural spine tumors performed at HVCs ( $>14$ procedures/10 years) were associated with improved postoperative outcomes. Technically, intradural spine tumors pose several challenges for neurosurgeons, the most obvious of which is the intended durotomy essential for tumor removal and exploration. ${ }^{31}$ Tumor resection requires a skill set independent of the techniques typical for spine procedures performed for degenerative pathologies..$^{31,41}$ Our findings indicate that patients treated at an LVC had an increased likelihood of inpatient mortality, unfavorable discharge, prolonged LOS, high-end hospital charges, DVT, and neurological, wound, and gastrointestinal complications compared with those treated at HVCs. The majority of HVCs were academic teaching centers, and the patients tended to be younger and have fewer comorbidities and a lower CCI. Although the CCI accounts for stratification of medical comorbidities in general, pertinent presurgical neurological issues that affect outcomes in patients with spine tumors, such as preoperative sensory and motor deficits, bladder/ bowel dysfunction, and presence of myelopathy or syrinx, were nearly equiproportionate among patients presenting to HVCs and those presenting to LVCs. Postoperatively, $4.4 \%$ of the patients at LVCs suffered a neurological deterioration, whereas only $2.0 \%$ of those in HVCs suffered a neurological complication ( $\mathrm{p}<0.0001)$. In our analysis, the preoperative drivers that increased the likelihood of a postoperative neurological complication were preoperative plegia (OR 2.02; 95\% CI 1.53-2.66; $\mathrm{p}<0.0001$ ), CAD (OR 1.91; 95\% CI 1.35-2.69; p < 0.0001), CRF (OR 3.62; 95\% CI 1.97-6.65; p < 0.0001), obesity (OR 1.55; 95\% CI 1.08-2.24; $\mathrm{p}=0.018$ ), PVD (OR 2.62; 95\% CI 1.48-4.64; $\mathrm{p}=0.001)$, and alcohol abuse (OR 2.26; 95\% CI 1.10-4.64; $\mathrm{p}=0.026$ ).

Limitations governing the use of administrative databases for retrospective analysis are well known ${ }^{48}$ and apply to the present study. The clinical information in the NIS is limited to patient demographics and comorbidities. Medical conditions and interventions are sequenced using ICD-9-CM codes for broad-based definitions of diseases and procedures, respectively. Although they provide baseline insights about patient hospitalization courses, data on individual patients cannot be trended based on severity of the disease/medical condition. Pertinent clinicoradiopathological information that is relevant to the present study but lacking in the NIS includes tumor size and location, histological variants and preoperative neurological grading, surgical approach and extent of resection, duration of intensive care unit stays, and reoperation for pseudomeningocele/CSF leaks. To this effect, our data did not delineate outcomes for benign tumors based on intramedullary and extramedullary definitions, which can affect baseline presurgical evaluation by the surgeon and thereby increase complexity of the surgery. Because of the lack of longitudinal follow-up and outpatient data in the NIS, our analysis was limited to an assessment of short-term inpatient outcomes only. In comparison with HVCs, the smaller number of patients undergoing surgery at LVCs may have predisposed this study to sampling bias and precludes a more detailed assessment of predictors or differences in these 2 cohorts. Human errors, including underreporting of events and coding inaccuracies, that may have affected our projected estimates ${ }^{12,54}$ cannot be ruled out. Despite several limitations, the NIS enables analyses of a random, stratified, and validated patient population across nonfederal US hospitals. These hospitals represent diverse clinical settings with respect to size, region, teaching status, and case volume, thus bolstering the generalizability of our findings. Although our analysis can be used as a baseline measure, future studies should address some of these issues with the creation of prospective registries.

\section{Conclusions}

Using the NIS, a prospective hospital discharge data- 
base, we identified independent associations with inpatient mortality, unfavorable discharge, prolonged LOS, highend hospital charges, neurological complications, DVT, $\mathrm{PE}$, wound complications, wound infection, and cardiac complications in patients undergoing surgery for benign intradural spine tumors. Comprising a representative, validated sample of inpatient admissions to nonfederal hospitals in the United States and enabling extrapolation to national statistics, the NIS provides statistical power while minimizing biases related to selection. All the predicted associations for the defined outcomes derived from regression models were tested for accuracy and are not purely a result of chance. With respect to the association of patient outcomes after intradural tumor resection, we observed that those who underwent the surgery at an HVC fared better than those who had it performed at an LVC in regard to inpatient mortality, unfavorable discharge, prolonged LOS, high-end hospital charges, DVT, and neurological, wound, and gastrointestinal complications. The quantification of these associated risks for short-term adverse events based on hospital case volume is demonstrated in our study. Although the association of these independent risk factors and the effect of hospital case volume on outcomes could serve as an essential tool in risk stratification, direct presurgical evaluation, assist surgical decision making, and strengthen the referral system for complex cases, generalizations should be made with caution and tailored on an individual basis.

\section{References}

1. Agency for Healthcare Research and Quality: Overview of the Nationwide Inpatient Sample (NIS). Healthcare and Utilization Project. (https://www.hcup-us.ahrq.gov/nisoverview. jsp) [Accessed June 4, 2015]

2. Aghayev K, Vrionis F, Chamberlain MC: Adult intradural primary spinal cord tumors. J Natl Compr Canc Netw 9:434-447, 2011

3. Alosh H, Riley LH III, Skolasky RL: Insurance status, geography, race, and ethnicity as predictors of anterior cervical spine surgery rates and in-hospital mortality: an examination of United States trends from 1992 to 2005. Spine (Phila Pa 1976) 34:1956-1962, 2009

4. Bardach NS, Zhao S, Gress DR, Lawton MT, Johnston SC: Association between subarachnoid hemorrhage outcomes and number of cases treated at California hospitals. Stroke 33:1851-1856, 2002

5. Barker FG II: Craniotomy for the resection of metastatic brain tumors in the U.S., 1988-2000: decreasing mortality and the effect of provider caseload. Cancer 100:999-1007, 2004

6. Barker FG II, Amin-Hanjani S, Butler WE, Ogilvy CS, Carter BS: In-hospital mortality and morbidity after surgical treatment of unruptured intracranial aneurysms in the United States, 1996-2000: the effect of hospital and surgeon volume. Neurosurgery 52:995-1009, 2003

7. Barker FG II, Carter BS, Ojemann RG, Jyung RW, Poe DS, McKenna MJ: Surgical excision of acoustic neuroma: patient outcome and provider caseload. Laryngoscope 113:13321343,2003

8. Barker FG II, Curry WT Jr, Carter BS: Surgery for primary supratentorial brain tumors in the United States, 1988 to 2000: the effect of provider caseload and centralization of care. Neuro Oncol 7:49-63, 2005

9. Barker FG II, Klibanski A, Swearingen B: Transsphenoidal surgery for pituitary tumors in the United States, 1996-2000: mortality, morbidity, and the effects of hospital and surgeon volume. J Clin Endocrinol Metab 88:4709-4719, 2003

10. Bearden D, Allman R, McDonald R, Miller S, Pressel S, Petrovitch H: Age, race, and gender variation in the utilization of coronary artery bypass surgery and angioplasty in SHEP. J Am Geriatr Soc 42:1143-1149, 1994

11. Berman MF, Solomon RA, Mayer SA, Johnston SC, Yung PP: Impact of hospital-related factors on outcome after treatment of cerebral aneurysms. Stroke 34:2200-2207, 2003

12. Berthelsen CL: Evaluation of coding data quality of the HCUP National Inpatient Sample. Top Health Inf Manage 21:10-23, 2000

13. Birkmeyer JD, Siewers AE, Finlayson EV, Stukel TA, Lucas FL, Batista I, et al: Hospital volume and surgical mortality in the United States. N Engl J Med 346:1128-1137, 2002

14. Boström A, Kanther NC, Grote A, Boström J: Management and outcome in adult intramedullary spinal cord tumours: a 20-year single institution experience. BMC Res Notes 7:908, 2014

15. Carey TS, Garrett JM: The relation of race to outcomes and the use of health care services for acute low back pain. Spine (Phila Pa 1976) 28:390-394, 2003

16. Chamberlain MC, Tredway TL: Adult primary intradural spinal cord tumors: a review. Curr Neurol Neurosci Rep 11:320-328, 2011

17. Charlson ME, Ales KL, Simon R, MacKenzie CR: Why predictive indexes perform less well in validation studies. Is it magic or methods? Arch Intern Med 147:2155-2161, 1987

18. Charlson ME, Pompei P, Ales KL, MacKenzie CR: A new method of classifying prognostic comorbidity in longitudinal studies: development and validation. J Chronic Dis 40:373383,1987

19. Cheung MC, Koniaris LG, Perez EA, Molina MA, Goodwin WJ, Salloum RM: Impact of hospital volume on surgical outcome for head and neck cancer. Ann Surg Oncol 16:10011009, 2009

20. Constantini S, Houten J, Miller DC, Freed D, Ozek MM, Rorke LB, et al: Intramedullary spinal cord tumors in children under the age of 3 years. J Neurosurg 85:1036-1043, 1996

21. Conti P, Pansini G, Mouchaty H, Capuano C, Conti R: Spinal neurinomas: retrospective analysis and long-term outcome of 179 consecutively operated cases and review of the literature. Surg Neurol 61:34-44, 2004

22. Cross DT III, Tirschwell DL, Clark MA, Tuden D, Derdeyn $\mathrm{CP}$, Moran CJ, et al: Mortality rates after subarachnoid hemorrhage: variations according to hospital case volume in 18 states. J Neurosurg 99:810-817, 2003

23. Curry WT, McDermott MW, Carter BS, Barker FG II: Craniotomy for meningioma in the United States between 1988 and 2000: decreasing rate of mortality and the effect of provider caseload. J Neurosurg 102:977-986, 2005

24. Dasenbrock HH, Clarke MJ, Witham TF, Sciubba DM, Gokaslan ZL, Bydon A: The impact of provider volume on the outcomes after surgery for lumbar spinal stenosis. Neurosurgery 70:1346-1354, 2012

25. Daumit GL, Hermann JA, Coresh J, Powe NR: Use of cardiovascular procedures among black persons and white persons: a 7-year nationwide study in patients with renal disease. Ann Intern Med 130:173-182, 1999

26. Dodd RL, Ryu MR, Kamnerdsupaphon P, Gibbs IC, Chang SD Jr, Adler JR Jr: CyberKnife radiosurgery for benign intradural extramedullary spinal tumors. Neurosurgery 58:674-685, 2006

27. Ebner FH, Roser F, Falk M, Hermann S, Honegger J, Tatagiba M: Management of intramedullary spinal cord lesions: interdependence of the longitudinal extension of the lesion and the functional outcome. Eur Spine J 19:665-669, 2010

28. Pan E, Prados MD: Spinal cord tumors, in Kufe DW, Pollock 
RE, Weichselbaum RR, et al (eds): Holland-Frei Cancer Medicine, ed 6. Hamilton, ON: BC Decker, 2003

29. Elsberg CA: Some aspects of the diagnosis and surgical treatment of tumors of the spinal cord: with a study of the end results in a series of 119 operations. Ann Surg 81:1057-1073, 1925

30. Englot DJ, Ouyang D, Wang DD, Rolston JD, Garcia PA, Chang EF: Relationship between hospital surgical volume, lobectomy rates, and adverse perioperative events at US epilepsy centers. J Neurosurg 118:169-174, 2013

31. Epstein FJ, Farmer JP, Freed D: Adult intramedullary spinal cord ependymomas: the result of surgery in 38 patients. $\mathbf{J}$ Neurosurg 79:204-209, 1993

32. Farjoodi P, Skolasky RL, Riley LH: The effects of hospital and surgeon volume on postoperative complications after LumbarSpine surgery. Spine (Phila Pa 1976) 36:2069-2075, 2011

33. Fisher ES, McClellan MB, Safran DG: Building the path to accountable care. N Engl J Med 365:2445-2447, 2011

34. Gezen F, Kahraman S, Canakci Z, Bedük A: Review of 36 cases of spinal cord meningioma. Spine (Phila Pa 1976) 25:727-731, 2000

35. Gittelsohn AM, Halpern J, Sanchez RL: Income, race, and surgery in Maryland. Am J Public Health 81:1435-1441, 1991

36. Gordon TA, Burleyson GP, Tielsch JM, Cameron JL: The effects of regionalization on cost and outcome for one general high-risk surgical procedure. Ann Surg 221:43-49, 1995

37. Groeneveld PW, Laufer SB, Garber AM: Technology diffusion, hospital variation, and racial disparities among elderly Medicare beneficiaries: 1989-2000. Med Care 43:320-329, 2005

38. Halm EA, Lee C, Chassin MR: Is volume related to outcome in health care? A systematic review and methodologic critique of the literature. Ann Intern Med 137:511-520, 2002

39. Harrop JS, Ganju A, Groff M, Bilsky M: Primary intramedullary tumors of the spinal cord. Spine (Phila Pa 1976) 34 (22 Suppl):S69-S77, 2009

40. Hoh BL, Rabinov JD, Pryor JC, Carter BS, Barker FG II: Inhospital morbidity and mortality after endovascular treatment of unruptured intracranial aneurysms in the United States, 1996-2000: effect of hospital and physician volume. AJNR Am J Neuroradiol 24:1409-1420, 2003

41. Johnston SC: Effect of endovascular services and hospital volume on cerebral aneurysm treatment outcomes. Stroke 31:111-117, 2000

42. Kalakoti P, Ahmed O, Bollam P, Missios S, Wilden J, Nanda A. Predictors of unfavorable outcomes following deep brain stimulation for movement disorders and the effect of hospital case volume on outcomes: an analysis of 33,642 patients across 234 US hospitals using the National (Nationwide) Inpatient Sample from 2002 to 2011. Neurosurg Focus 38(6):E4, 2015

43. Kalkanis SN, Eskandar EN, Carter BS, Barker FG II: Microvascular decompression surgery in the United States, 1996 to 2000: mortality rates, morbidity rates, and the effects of hospital and surgeon volumes. Neurosurgery 52:1251-1262, 2003

44. Kaufman JS, Cooper RS, McGee DL: Socioeconomic status and health in blacks and whites: the problem of residual confounding and the resiliency of race. Epidemiology 8:621628,1997

45. Khuri SF, Daley J, Henderson W, Hur K, Hossain M, Soybel $\mathrm{D}$, et al: Relation of surgical volume to outcome in eight common operations: results from the VA National Surgical Quality Improvement Program. Ann Surg 230:414-432, 1999

46. Klekamp J, Samii M: Surgery of spinal nerve sheath tumors with special reference to neurofibromatosis. Neurosurgery 42:279-290, 1998
47. Kumar R, Banerjee S: Management and functional outcome of intramedullary spinal cord tumors: A prospective clinical study. Asian J Neurosurg 9:177-181, 2014

48. Lawthers AG, McCarthy EP, Davis RB, Peterson LE, Palmer $\mathrm{RH}$, Iezzoni LI: Identification of in-hospital complications from claims data. Is it valid? Med Care 38:785-795, 2000

49. Lee SM, Cho YE, Kwon YM: Neurological outcome after surgical treatment of intramedullary spinal cord tumors. Korean J Spine 11:121-126, 2014

50. Matsuyama Y, Sakai Y, Katayama Y, Imagama S, Ito Z, Wakao N, et al: Surgical results of intramedullary spinal cord tumor with spinal cord monitoring to guide extent of resection. J Neurosurg Spine 10:404-413, 2009

51. Miller DJ, McCutcheon IE: Hemangioblastomas and other uncommon intramedullary tumors. J Neurooncol 47:253270,2000

52. Nambiar M, Kavar B: Clinical presentation and outcome of patients with intradural spinal cord tumours. J Clin Neurosci 19:262-266, 2012

53. Nwachukwu BU, Kenny AD, Losina E, Chibnik LB, Katz JN: Complications for racial and ethnic minority groups after total hip and knee replacement: a review of the literature. $\mathbf{J}$ Bone Joint Surg Am 92:338-345, 2010

54. O'Malley KJ, Cook KF, Price MD, Wildes KR, Hurdle JF, Ashton CM: Measuring diagnoses: ICD code accuracy. Health Serv Res 40:1620-1639, 2005

55. Parsa AT, Lee J, Parney IF, Weinstein P, McCormick PC, Ames C: Spinal cord and intradural-extraparenchymal spinal tumors: current best care practices and strategies. J Neurooncol 69:291-318, 2004

56. Parsa AT, McCormick PC: Intramedullary Spinal Tumors. Philadelphia: Saunders, 2006

57. Patil CG, Patil TS, Lad SP, Boakye M: Complications and outcomes after spinal cord tumor resection in the United States from 1993 to 2002. Spinal Cord 46:375-379, 2008

58. Romano PS, Roos LL, Jollis JG: Adapting a clinical comorbidity index for use with ICD-9-CM administrative data: differing perspectives. J Clin Epidemiol 46:1075-1090, 1993

59. Seppälä MT, Haltia MJ, Sankila RJ, Jääskeläinen JE, Heiskanen O: Long-term outcome after removal of spinal neurofibroma. J Neurosurg 82:572-577, 1995

60. Seppälä MT, Haltia MJ, Sankila RJ, Jääskeläinen JE, Heiskanen O: Long-term outcome after removal of spinal schwannoma: a clinicopathological study of 187 cases. J Neurosurg 83:621-626, 1995

61. Sharma M, Sonig A, Ambekar S, Nanda A: Discharge dispositions, complications, and costs of hospitalization in spinal cord tumor surgery: analysis of data from the United States Nationwide Inpatient Sample, 2003-2010. J Neurosurg Spine 20:125-141, 2014

62. Skinner J, Weinstein JN, Sporer SM, Wennberg JE: Racial, ethnic, and geographic disparities in rates of knee arthroplasty among Medicare patients. N Engl J Med 349:1350-1359, 2003

63. Smith ER, Butler WE, Barker FG II: Craniotomy for resection of pediatric brain tumors in the United States, 1988 to 2000: effects of provider caseloads and progressive centralization and specialization of care. Neurosurgery 54:553565,2004

64. Smith ER, Butler WE, Barker FG II: In-hospital mortality rates after ventriculoperitoneal shunt procedures in the United States, 1998 to 2000: relation to hospital and surgeon volume of care. J Neurosurg 100 (2 Suppl Pediatrics):90-97, 2004

65. Steiner C, Elixhauser A, Schnaier J: The healthcare cost and utilization project: an overview. Eff Clin Pract 5:143-151, 2002

66. Taylor BA, Casas-Ganem J, Vaccaro AR, Hilibrand AS, Hanscom BS, Albert TJ: Differences in the work-up and 
treatment of conditions associated with low back pain by patient gender and ethnic background. Spine (Phila Pa 1976) 30:359-364, 2005

67. Tihan T, Chi JH, McCormick PC, Ames CP, Parsa AT: Pathologic and epidemiologic findings of intramedullary spinal cord tumors. Neurosurg Clin N Am 17:7-11, 2006

68. Tobias ME, McGirt MJ, Chaichana KL, Goldstein IM, Kothbauer KF, Epstein F, et al: Surgical management of long intramedullary spinal cord tumors. Childs Nerv Syst 24:219-223, 2008

69. Woodworth GF, Chaichana KL, McGirt MJ, Sciubba DM, Jallo GI, Gokaslan Z, et al: Predictors of ambulatory function after surgical resection of intramedullary spinal cord tumors. Neurosurgery 61:99-106, 2007

70. Xu Q, Bao W, Mao R: Microsurgery of intramedullary cervical cord tumor. Chin Med J (Engl) 109:756-761, 1996

71. Xu QW, Bao WM, Mao RL, Yang GY: Aggressive surgery for intramedullary tumor of cervical spinal cord. Surg Neurol 46:322-328, 1996
72. Yang S, Yang X, Hong G: Surgical treatment of one hundred seventy-four intramedullary spinal cord tumors. Spine (Phila Pa 1976) 34:2705-2710, 2009

\section{Author Contributions}

Conception and design: Kalakoti. Acquisition of data: Kalakoti, Missios. Analysis and interpretation of data: Kalakoti. Drafting the article: Kalakoti, Menger. Critically revising the article: Kalakoti, Missios. Reviewed submitted version of manuscript: all authors. Approved the final version of the manuscript on behalf of all authors: Nanda. Statistical analysis: Kalakoti, Missios. Administrative/technical/material support: Nanda, Kalakoti, Kukreja, Konar. Study supervision: Nanda, Kalakoti, Missios.

\section{Correspondence}

Anil Nanda, Department of Neurosurgery, Louisiana State Health Sciences Center-Shreveport, P.O. Box 33932, 1501 Kings Hwy., Shreveport, LA 71130-3932. email: ananda@1suhsc.edu. 